\title{
Multicentric Castleman's Disease
}

\author{
Surg Capt MK Gupta ${ }^{*}$, Lt Col SK Magu ${ }^{+}$, Surg Cdr A Behl vsm ${ }^{\#}$
}

MJAFI 2002; $58: 250-252$

Key Words :Angiofollicular hyperplasia; Lymph node.

Introduction

astleman's disease is a rare, atypical lymphoproliferative disorder that is morphologically and clinically heterogeneous and is associated with a risk of developing malignant lymphoma. It represents a distinct form of lymph node hyperplasia rather than a neoplasm or a hamartoma. In Castleman's original report, this lesion was described as solitary and confined to mediastinum that resembled thymomas both clinically and histologically [1]. Since then the disease has been reported in many other locations including abdominal cavity, pulmonary parenchyma, axillary and cervical region and skeletal muscles. Two forms of disease exist : the localized type which is more common; and the more recently described rare multicentric or systemic form [2]. We report a case of multicentric Castleman's Disease in an elderly lady with an unusual presentation of massive ascites and pedal oedema. We have not found a similar report despite an extensive literature search.

\section{Case Report}

A 65 year old female presented with generalized lymphadenopathy, ascites and pedal oedema for which she reported to a civil hospital one and a half years back. Fine needle aspiration cytology of retroperitoneal lymph node done there was reported as tuberculous lymphadenitis. She received antituberculous treatment (ATT) (EHRZ) for one year but continued to have generalized lymphadenopathy and ascites. Thereafter she got admitted in a Command Hospital of Army where ultrasonography of abdomen revealed ascites, splenomegaly and cholelithiasis. Therapeutic abdominal paracentesis and an axillary lymph node biopsy were reported as reactive follicular hyperplasia. ATT therapy was restarted and she was advised follow up.

lnspite of ATT she continued to deteriorate and was brought to this hospital. On examination she weighed 45 $\mathrm{Kg}$, temp $99^{\circ} \mathrm{F}$, pulse rate $106 / \mathrm{min}$, BP $150 / 80 \mathrm{~mm} \mathrm{Hg}$ and respiratory rate was $18 / \mathrm{min}$. She had pallor and bilateral pitting oedema. Bilaterally, cervical and axillary group of Jymph nodes were enlarged, soft, mobile, non-tender, discrete and of varying size. She was also found to have massive ascites, splenomegaly of $6 \mathrm{~cm}$ and hepatomegaly of 3 $\mathrm{cm}$.
Investigations revealed $\mathrm{Hb}-9.0 \mathrm{gm} \%$, TLC- $12,300 / \mathrm{cmm}$, DLC-P65, L31, M02, E02, ESR-30 $\mathrm{mm} 1^{\text {st }}$ hour. Serum bilirubin-1.4 mg/dl, serum albumin-2.6 gm/dl, globulin-4.6 gm/dl. A:G ratio-1:1.7, SGOT-65 IU/L, SGPT-42 IU/L. alkaline phosphatase-449 IU/L. Urine R/E., blood sugar, utea. creatinine, electrolytes, total proteins were within normal limits. Tests for HIV, HbsAg and syphilis were negative. $\mathrm{X}$-ray chest was normal, USG abdomen revealed ascites, cholelithiasis, grade I fatty infiltration liver, splenomegaly and lymph node enlargement in peripancreatic, portal and para-aortic areas. Bone marrow examination showed reactive bone marrow picture, ascitic fluid analysis revealed yellow coloured fluid, specific gravity 1019 , proteins 4.4 $\mathrm{gm} / \mathrm{dl}$, cells $400 / \mathrm{cmm}$ predominantly lymphocytes, no malignant cells, bacteria or fungi were seen.

In our hospital, a repeat axillary lymph node biopsy done revealed altered nodal architecture due to increased number of varying sized lymphoid follicles evenly distributed throughout in a prominently vascularised parenchyma. The follicles showed peripheral concentric layering of small, uniform, mature lymphocytes; the "onion skin" appearance (Fig-1). Germinal centres of few follicles appeared transfixed by radiating penetrating capillaries forming the characteristic "lolly-pop" structures (Fig-2). Interfollicular regions contained dense plasma cell infiltrate intermingled with some lymphocytes, few immunoblasts and occasional eosinophils (Fig-3). Both mitoses and lymph node sinuses were inconspicuous. Histopathology of lymph node was diagnostic of Castleman's disease-plasma cell type.

\section{Discussion}

Castleman's disease is a rare disorder characterised by noncancerous growth that may develop in lymph node tissue. Most often the disease is localised. Histologically, there are two major types of localised Castleman's disease; the hyaline-vascular type and the plasma cell type [3]. The hyaline-vascular type accounts for approximately $90 \%$ of the cases. Most individuals exhibit no symptoms in this type, in contrast to the plasma cell type, which may present with a wide variety of inexplicable symptoms and abnormal laboratory findings. Differential diagnosis of hyaline vascular type of Castleman's disease includes Castleman's like lesions seen in HIV related persistent generalized lymphadenopathy, plasmacytoma, follicular

\footnotetext{
Senior Adviser (Pathology), ${ }^{+}$Classified Specialist (Pathology), "Classified Specialist (Surgery and Oncosurgery), INHS Asvini, Colaba, Mumbai-400005.
} 


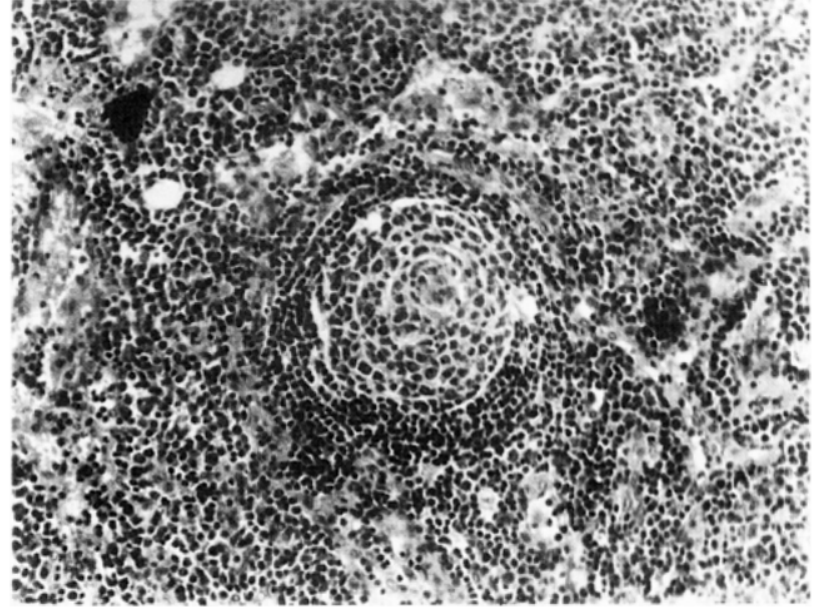

Fig, 1 : Castleman's disease - microphotograph of lymph node showing concentric tayering of small lymphocytes, the "onion-skin appearance"

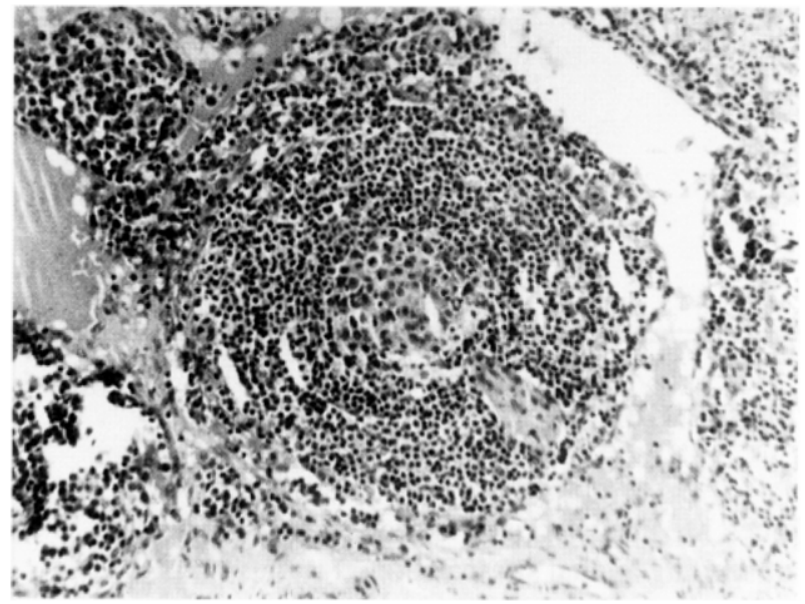

Fig. 2 : Germinal centre of bymph node follicle transfixed by radiating penetrating capillary, the "lolly-pop" structure, seen typically in Castleman's disease. Note the hypervascularity of interfollicular tissue (H\&E; low power)

lymphoma and Hodgkin's disease. Plasma cell variant has to be differentiated from other follicular hyperplasias with prominent interfollicular plasmacytosis, such as those associated with rheumatoid arthritis and other autoimmune disorders, and syphilis.

Multicentric form of Castleman's disease is the least common. Mostly it is of plasma cell type but mixed cell type showing features of both hyaline type and plasma cell type can occur. It affects more than one area of body and may exhibit hepatosplenomegaly. The diagnosis of systemic Castleman's disease is one of exclusion and other disorders that produce similar histologic changes must be ruled out. The patients are older ( 57 years median age) than those with the localised disease, peripheral lymph nodes are always involved and the development of malignancies is common. Frizzera defines this disor-

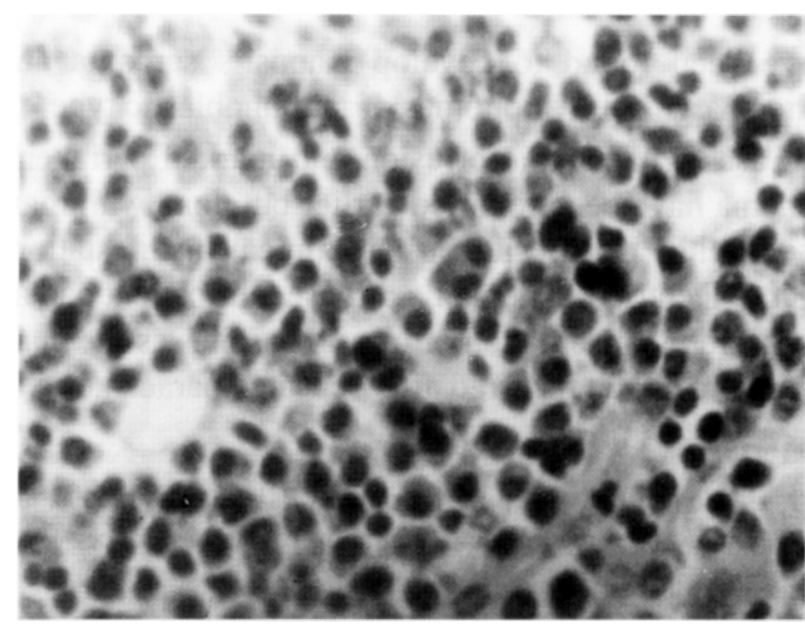

Fig. 3: Plasma cell variant of Castleman's disease. The interfollicular tissue contains Jarge number of plasma cells (H\&E; high power)

der by a combination of four clinicopathologic criteria:

1. The characteristic histologic features of plasma cell type of disease.

2. A predominantly lymphadenopathic disease involving multiple lymphnodes, mostly peripheral nodes.

3. Various manifestations of multisystem involvement.

4. An idiopathic nature [4].

The clinical and laboratory features of Castleman's disease are similar to those of angioimmunoblastic lymphadenopathy, suggesting a related pathogenesis resulting from an abnormal immune response. Many of the cells in abnormal germinal centres and in intervening tissue have phenotypical features of follicular dendritic cells, suggesting a dysfunction of these antigen presenting cells as a cause in pathogenesis of this disorder. Molecular analysis of clonality in Castleman's disease reveals polyclonal VH-JH and Vgama Jgama rearrangements irrespective of pathologic subtypes and clinical forms. The lymphoid component in Castleman's disease is therefore commonly reactive [5]. Abundant expression of interleukin-6 that has been detected in this condition is thought to be responsible for the marked plasma cell infiltration $[6,7]$.

The clinical course of this disorder varies. It may behave like a chronic disease with a persistent or relapsing pattern or else like an unremitting aggressive lymphoproliferative disorder that may be fatal. The long term prognosis of multicentric Castleman's disease is poor : the disease tends to persist for months or years and sometimes results in renal or pulmonary complications. Further more, some of the patients 
have been found to develop Kaposi's sarcoma and others large cell lymphomas of immunoblastic type.

Cases with pleural effusion and marked peripheral oedema have been reported earlier but none with massive ascites [7]. Besides usual clinical manifestations of multicentric Castleman's disease, our patient had an uncommon presentation of massive ascites as the main symptom which recurred after repeated paracentesis.

\section{References}

I. Castleman B, Iverson I, Menendez VP. Localized mediastinal lymph node hyperplasia resembling thymoma, Cancer 1956; 9:822.

2. Frizzera G, Peterson BA, Bayrd ED, Goldman A. Systemic lymphoproliferative disorder with morphological features of Castleman disease : clinical findings and clinicopathologic correlations in 15 patients. J Clin Oncol 1985;3:1202-16.

3. Keller AR, Hochholzer L, Castleman B. Hyaline -vascular and plasma-cell types of giant lymph node hyperplasia of mediastinum and other locations. Cancer 1972;29:670-83.

4. Frizzera G. Castleman's disease and related disorders. Semin Diagn Pathol 1988;5:346.

5. Soulier J, Grollet L, Oksenhendler E, Miclea JM, Cacoub P, Baruchel A et al. Molecular analysis of clonality in Castleman's disease. Blood 1995:86(3):1131-8.

6. Hsu SM, Waldron JA, Xie SS, Barlogie B. Expression of interleukin-6 in Castleman's disease. Hum Pathol 1993;24: 833-9.

7. Rieu P, Droz D, Gessain A, Grunfeld JP. Hermine O. Retinoic acid for treatment of multicentric Castleman's disease. The Lancet 1999;354:1262-3. 